\title{
PENGARUH WAKTU PEMANASAN TERHADAP SINTESIS NANOPARTIKEL $\mathrm{FE}_{3} \mathrm{O}_{4}$
}

\author{
Astuti, Aso Putri Inayatul Hasanah \\ Jurusan Fisika. FMIPA. Universitas Andalas \\ Email: tuty_phys@yahoo.com
}

\begin{abstract}
ABSTRAK
Nanopartikel magnetik $\mathrm{Fe}_{3} \mathrm{O}_{4}$ disintesis dari destruksi batuan besi. Metode yang digunakan adalah metode kopresipitasi dengan menggunakan template PEG 4000. Penelitian ini bertujuan untuk menganalisis pengaruh waktu pemanasan terhadap sifat nanopartikel magnetik yang dihasilkan, yaitu 3 jam, 4 jam, dan 5 jam pada temperatur $220{ }^{\circ} \mathrm{C}$. Karakterisassi nanopartikel magnetik dilakukan dengan Magnetic Susceptibilitymeter, X-Ray Difractometer (XRD), dan Scanning Elektron Microscope (SEM). Berdasarkan hasil penelitian ini, waktu dan temperatur pemanasan berpengaruh terhadap kemagnetan, ukuran partikel, maupun ukuran kristal material magnetik $\mathrm{Fe}_{3} \mathrm{O}_{4}$ yang dihasilkan. Pemanasan dengan waktu yang optimum diperoleh pada 4 jam dengan ukuran kristal 20,86 $\mathrm{nm}$ dan ukuran partikel terkecil antara 36-46 nm dan suseptibilitas magnetnya $20427,96 \times 10^{-8} \mathrm{~m}^{3} / \mathrm{kg}$. Sedangkan distribusi ukuran partikel sudah cukup seragam dan berbentuk bulat, sebagai pengaruh dari PEG 4000 yang berfungsi sebagai template dan mencegah terjadinya aglomerasi antar partikel.
\end{abstract}

Kata kunci : Nanopartikel magnetik, $\mathrm{Fe}_{3} \mathrm{O}_{4}$, PEG-4000, waktu pemanasan.

\section{PENDAHULUAN}

Besi merupakan unsur logam yang berasal dari bijih besi yang banyak terdapat pada daerah pegunungan. Besi banyak dimanfaatkan oleh manusia karena pengolahanya yang relatif murah dan mudah serta besi mempunyai sifat-sifat yang menguntungkan dan mudah dimodifikasi. Penggunaan besi sangat beragam, mulai dari keperluan rumah, pertanian, permesinan hingga untuk alat transportasi. Di alam, biji besi dapat ditemukan dalam bentuk mineral magnetit $\left(\mathrm{Fe}_{3} \mathrm{O}_{4}\right)$ (Hunt dkk, 1995). Luasnya aplikasi dari $\mathrm{Fe}_{3} \mathrm{O}_{4}$ ternyata tidak terlepas dari perkembangan kajian nanomaterial yaitu material dengan ukuran dalam orde nanometer $(\mathrm{nm})$, atau kurang dari $100 \mathrm{~nm}$. Beberapa sifat nanopartikel magnetik bergantung pada ukurannya. Sebagai contoh, ketika ukuran suatu partikel magnetik di bawah $10 \mathrm{~nm}$ akan bersifat superparamagnetik pada temperatur ruang, artinya energi termal dapat menghalangi anisotropi energi penghalang dari sebuah nanopartikel tunggal. Sintesis nanopartikel seragam dengan mengatur ukurannya menjadi salah satu kajian yang sangat menarik akhir-akhir ini (Aiguo dkk, 2008).

Penelitian-penelitian tentang nanopartikel magnetik banyak dimanfaatkan dalam industri keramik, katalis, energy storage, magnetic data storage, ferofluida, absorbent, serta biomedis. Misalnya di bidang biomedis, nanopartikel magnet digunakan untuk treatment hyperthermia yaitu peyembuhan penyakit tumor, drug delivery system sebagai contrast agent dalam diagnosa penyakit dengan menggunakan magnetic resonance imaging (MRI). Sedangkan dalam bidang industri digunakan sebagai katalis, sensor, penyimpan data dalam bentuk CD atau hard disk, pigmen warna (Takayanagi, dkk, 2007; Perdana, dkk, 2010; Lida, dkk, 2007).

Nanopartikel $\mathrm{Fe}_{3} \mathrm{O}_{4}$ biasanya didapat dengan beberapa metode sintesis kimia, seperti kopresipitasi, reverse micelle method, sintesis microwave plasma, teknik sol-gel, freeze drying, ultrasound irradiaton, metode hidrotermal, teknik pirolisis laser, dan lain-lain (Aiguo dkk, 2008; Sholiha, dkk, 2010). Metode kopresipitasi merupakan metode sintesis 
yang paling sederhana, mudah dan tidak membutuhakan temperatur yang tinggi, namun dapat menghasilkan partikel $\mathrm{Fe}_{3} \mathrm{O}_{4}$ dalam orde nanometer.

Selain material yang digunakan, proses selama sintesis juga mempengaruhi ukuran partikel. Temperatur sintering dan waktu sintering merupakan variabel yang sangat berpengaruh terhadap ukuran partikel. Oleh sebab itu dalam penelitian ini melaporkan sintesis nanopartikel magnetik dengan menggunakan optimasi waktu pemanasan pada temperature rendah. Selain itu, juga digunakan PEG 4000 sebagai template, yang dapat mencegah terjadinya aglomerasi sehingga dihasilkan distribusi ukuran partikel yang lebih kecil dibandingkan dengan menggunakan temperatur tinggi. Serbuk magnetik yang terbentuk berwarna hitam dan dapat ditarik oleh magnet. Kemagnetan serbuk ini diuji dengan menggunakan Magnetic Susceptibility Meter (dual frequency sensor model MS2B), dan morfologi partikel diamati dengan Scanning Electron Microscopy (SEM, JEOL JSM-6360LA), sedangkan kristalinitasnya dikarakterisasi dengan menggunakan Xray diffraction (XRD, Rigaku D/max $2550 \mathrm{~V}$ ), selain struktur kristal, data XRD juga dapat digunakan untuk menentukan ukuran kristal yaitu menggunakan persamaan Scherrer pada Persamaan 1.

$$
D=\frac{k \cdot \lambda}{B \cos \theta_{B}}
$$

dengan :

$$
\begin{aligned}
D= & \text { Ukuran kristal } \\
\lambda= & \text { Panjang gelombang sinar-X yang digunakan } \\
\theta_{B}= & \text { Sudut Bragg, B adalah FWHM (Full Width at Half Maximum) pada } 2 \theta \mathrm{x} \\
& (\pi / 180) \text { satu puncak yang dipilih, } \\
k= & \begin{array}{c}
\text { Konstanta material yang nilainya kurang dari satu. Nilai yang umumnya } \\
\text { dipakai untuk } k \text { adalah } 0,9 .
\end{array}
\end{aligned}
$$

\section{METODE PENELITIAN}

Serbuk $\mathrm{Fe}_{3} \mathrm{O}_{4}$ sebanyak 10 gram dilarutkan dalam $\mathrm{HCl}(12 \mathrm{M})$ sebanyak $20 \mathrm{ml}$ pada temperatur $90{ }^{\circ} \mathrm{C}$ dan diaduk sekitar 60 menit dengan magnetic stirrer.

Setelah larutan terbentuk, dilakukan penyaringan menggunakan kertas saring. Hasil dari larutan yang telah disaring tadi berupa filtrat. Untuk mengendapkan filtrat ditambahkan $\mathrm{NH}_{4} \mathrm{OH}$ sebanyak $25 \mathrm{ml}$ dan didiamkan selama 30 menit sehingga diperoleh endapan. PEG-4000 dilelehkan pada temperatur $40^{\circ} \mathrm{C}$, kemudian ditambahkan dalam endapan $\mathrm{Fe}_{3} \mathrm{O}_{4}$ diaduk. Endapan $\mathrm{Fe}_{3} \mathrm{O}_{4}$ yang terbentuk (berwarna hitam pekat) dipisahkan dari larutannya dan dicuci dengan menggunakan aquades 3 kali, kemudian dikeringkan dalam oven pada temperatur $220^{\circ} \mathrm{C}$ dengan variasi waktu 3 jam, 4 jam, dan 5 jam.

\section{HASIL DAN PEMBAHASAN}

\section{a. Analisis Data Magnetic Susceptibility}

Hasil pengukuran suseptibilitas magnet dari ketiga sampel serbuk magnetik dapat dilihat pada Tabel. 1. 
Tabel 1. Hasil pengukuran Suseptibilitas serbuk $\mathrm{Fe}_{3} \mathrm{O}_{4}$ dengan waktu pemanasan 3 jam, 4 jam dan 5 jam.

\begin{tabular}{lc}
\hline \multicolumn{1}{c}{ Sampel } & Suseptibilitas Magnet $\left(10^{-8} \mathrm{~m}^{3} / \mathrm{kg}\right)$ \\
\hline $\begin{array}{l}\mathrm{Fe}_{3} \mathrm{O}_{4} \text { dengan waktu } \\
\text { pemanasan 3 jam }\end{array}$ & 76711,08 \\
\hline $\begin{array}{l}\mathrm{Fe}_{3} \mathrm{O}_{4} \text { dengan waktu } \\
\text { pemanasan 4 jam }\end{array}$ & 20427,96 \\
\hline $\begin{array}{l}\mathrm{Fe}_{3} \mathrm{O}_{4} \text { dengan waktu } \\
\text { pemanasan 5 jam }\end{array}$ & 118942.42 \\
\hline
\end{tabular}

Berdasarkan data pada Tabel 4.1 dapat disimpulkan bahwa mineral utama penyusun batuan besi pada waktu pemanasan 3 jam, 4 jam dan 5 jam adalah magnetit $\left(\mathrm{Fe}_{3} \mathrm{O}_{4}\right)$. Hal ini dapat dilihat dari nilai suseptibilitas magnet dari ketiga sampel berada dalam rentang nilai suseptibilitas magnetit yaitu 20.000-140.000 x $10^{-8} \mathrm{~m}^{3} / \mathrm{kg}$ yang bersifat Ferimagnetik. Ferimagnetik bersifat keras dan tahan terhadap panas dan zat kimia.

\section{b. Analisis Data Difraksi sinar-X (XRD)}

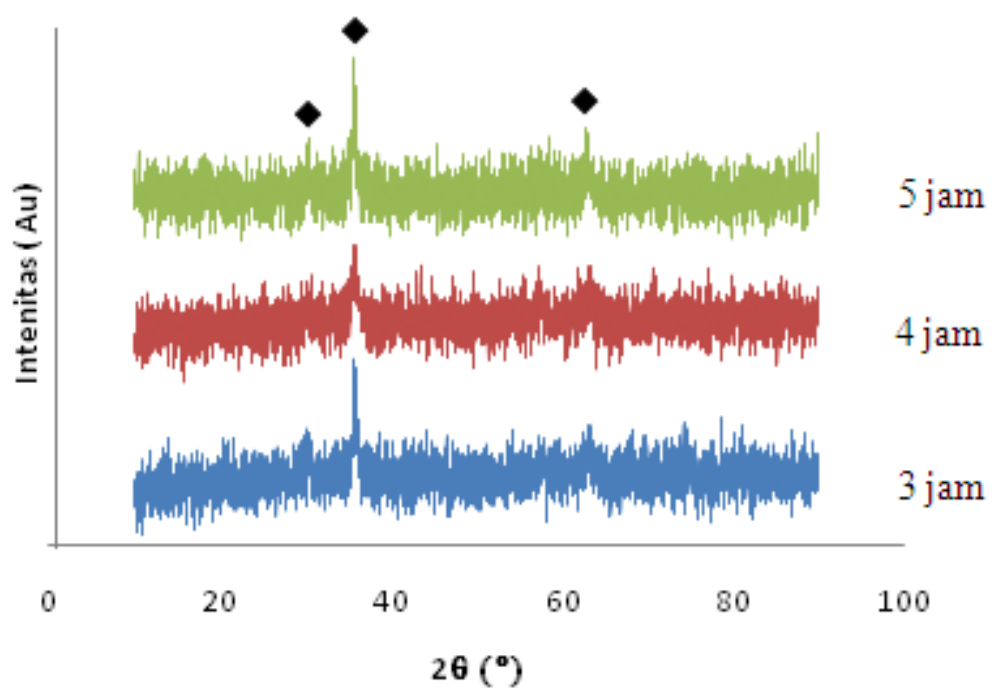

Gambar 1. Pola difraksi sinar- $\mathrm{X}$ dari $\mathrm{Fe} 3 \mathrm{O} 4$ dengan variasi waktu pemanasan

Gambar 1. menunjukkan pola difraksi XRD dari sampel $\mathrm{Fe}_{3} \mathrm{O}_{4}$ dengan penambahan PEG-4000 dengan lamanya pemanasan yang bervariasi yaitu pada waktu 3 jam, 4 jam dan 5 jam. Pada gambar terlihat puncak-puncak tertinggi dari sampel yang kemudian dicocokkan dengan Tabel Hanawalt 79-0417. berdasarkan tabel Hanawalt diketahui struktur kristal $\mathrm{Fe}_{3} \mathrm{O}_{4}$ adalah kubik dengan parameter kisi adalah $\mathrm{a}=\mathrm{b}=\mathrm{c}=8,394 \AA$, $\alpha=$ $\beta=\gamma=90^{\circ}$. Tiga puncak tertinggi dari pola difraksi sinar-X hasil penelitian ini adalah pada nilai d sama dengan 2,5182 $\AA, 2,5161 \AA$ dan 2,5226 ̊. Berdasarkan data ICSD No. 065339 menunjukkan bahwa sampel mengandung fasa $\mathrm{Fe}_{3} \mathrm{O}_{4}$ dan tidak ditemukannya fasa lain. Ini berarti tidak ditemukan adanya fasa PEG dalam sampel, yang menandakan bahwa PEG-4000 tidak ikut bereaksi dan hanya bertindak sebagai template saja.

Lebarnya puncak dari masing-masing sampel menunjukkan banyaknya sinar-X yang terhambur pada bidang $\mathrm{d}_{\mathrm{hkl}}$ yang sama. Lebar dari pola XRD mengindentifikasi ukuran 
kristal dari suatu sampel. Ukuran kristal dapat dihitung dengan mengetahui lebar setengah puncak maksimum ( FWHM ). Sampel yang memiliki FWHM yang lebar memiliki ukuran kristal yang lebih kecil. Berdasarkan hasil penelitian ini diperoleh sampel dengan FWHM yang paling lebar adalah sampel dengan pemanasan 4 jam.

Secara kuantitatif, ukuran kristal tersebut dapat dihitung dengan menggunakan persamaan Scherrer, sehingga didapatkan ukuran kristal masing-masing sampel pada Table. 2

Tabel 2. Ukuran kristal masing-masing sampel

\begin{tabular}{lc}
\hline \multicolumn{1}{c}{ Sampel } & $\begin{array}{c}\text { Ukuran kristal } \\
(\mathrm{nm})\end{array}$ \\
\hline $\begin{array}{l}\mathrm{Fe}_{3} \mathrm{O}_{4} \text { dengan waktu } \\
\text { pemanasan 3 jam }\end{array}$ & 41,84 \\
\hline $\begin{array}{l}\mathrm{Fe}_{3} \mathrm{O}_{4} \text { dengan waktu } \\
\text { pemanasan 4 jam }\end{array}$ & 20,86 \\
\hline $\begin{array}{l}\mathrm{Fe}_{3} \mathrm{O}_{4} \text { dengan waktu } \\
\text { pemanasan 5 jam }\end{array}$ & 69,67 \\
\hline
\end{tabular}

Berdasarkan Tabel 2, terbukti bahwa lebar puncak difraksi sinar-X tersebut menggambarkan ukuran kristal. Partikel $\mathrm{Fe}_{3} \mathrm{O}_{4}$ dengan lama pemanasan 5 jam, memiliki ukuran kristal yang paling besar dibandingkan dengan sampel yang lain. Hal ini disebabkan oleh pemanasan yang terlalu lama, sehingga terjadi pertumbuhan kristal $\mathrm{Fe}_{3} \mathrm{O}_{4}$. Pemanasan yang dilakukan selama 4 jam sangat efektif karena menghasilkan ukuran kristal yang paling kecil yaitu 20,86 nm.

\section{c. Analisis morfologi data Scanning Electron Microscope (SEM)}

Hasil SEM menunjukkan bahwa partikel yang terbentuk mempunyai morfologi yang sama yaitu bulat (spherical). Hal ini sama dengan hasil penelitian sebelumnya yang dilakukan oleh Perdana, dkk (2010). Rantai PEG-4000 akan menyebabkan permukaan nanopartikel $\mathrm{Fe}_{3} \mathrm{O}_{4}$ terlapisi, sehingga pertumbuhannya terbatasi ke segala arah.

Morfologi partikel $\mathrm{Fe}_{3} \mathrm{O}_{4}$ dengan variasi lama pemanasan 3 jam pada temperatur $220{ }^{\circ} \mathrm{C}$ ditunjukkan oleh Gambar 2. Hasil SEM menunjukkan bahwa distribusi ukuran partikelnya tidak seragam dan banyak partikel yang menggumpal. Distribusi ukuran partikel dari sampel didominasi oleh ukuran antara 50-60 nm.

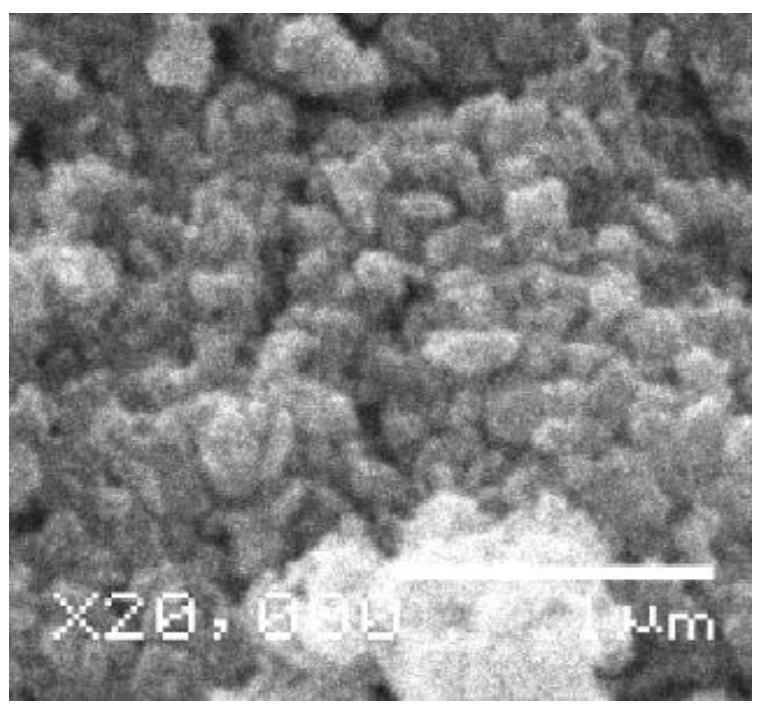

Gambar 2. Morfologi sampel Fe3O4 dengan lama pemanasan 3 jam 
Morfologi partikel $\mathrm{Fe}_{3} \mathrm{O}_{4}$ dengan lama pemanasan 4 jam pada temperatur sintering 220 ${ }^{0} \mathrm{C}$ ditunjukkan oleh Gambar 3. Nanopartikel $\mathrm{Fe}_{3} \mathrm{O}_{4}$ yang terbentuk terlihat cukup seragam dan ukurannya lebih kecil daripada ukuran nanopartikel $\mathrm{Fe}_{3} \mathrm{O}_{4}$ dengan lama pemanasan 3 jam. Diameter ukuran partikel dari sampel dengan lama pemanasan 4 jam berkisar antara 25 - $68 \mathrm{~nm}$, dan didominasi oleh nanopartikel dengan ukuran antara 36 $46 \mathrm{~nm}$.

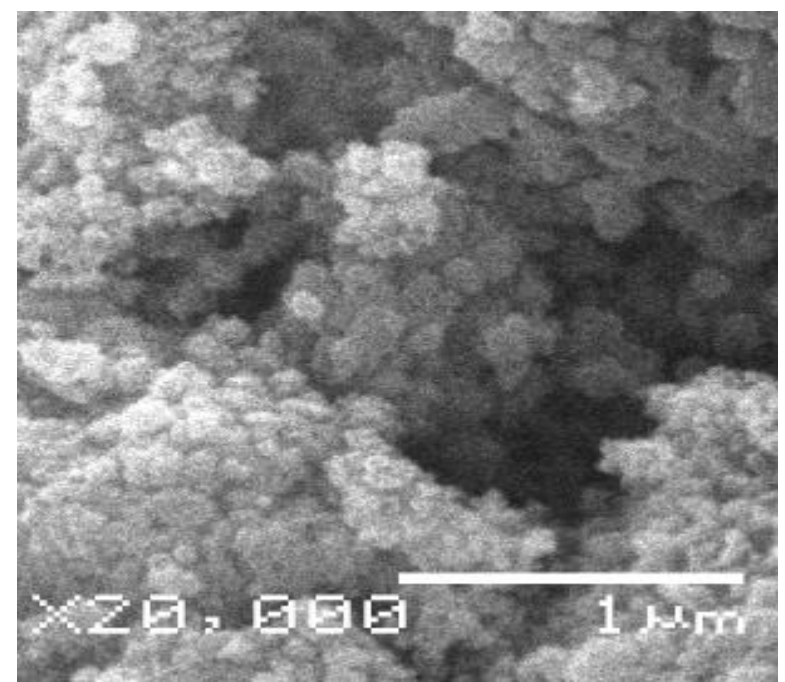

Gambar 3. Morfologi sampel $\mathrm{Fe}_{3} \mathrm{O}_{4}$ dengan lama pemanasan 4 jam

Morfologi partikel $\mathrm{Fe}_{3} \mathrm{O}_{4}$ dengan lama pemanasan 5 jam pada temperatur $220{ }^{\circ} \mathrm{C}$ ditunjukkan oleh Gambar 4. Nanopartikel $\mathrm{Fe}_{3} \mathrm{O}_{4}$ yang terbentuk mempunyai ukuran cukup seragam. Diameter ukuran partikel dari 36-79 $\mathrm{nm}$ didominasi oleh ukuran partikel antara $58-68 \mathrm{~nm}$.

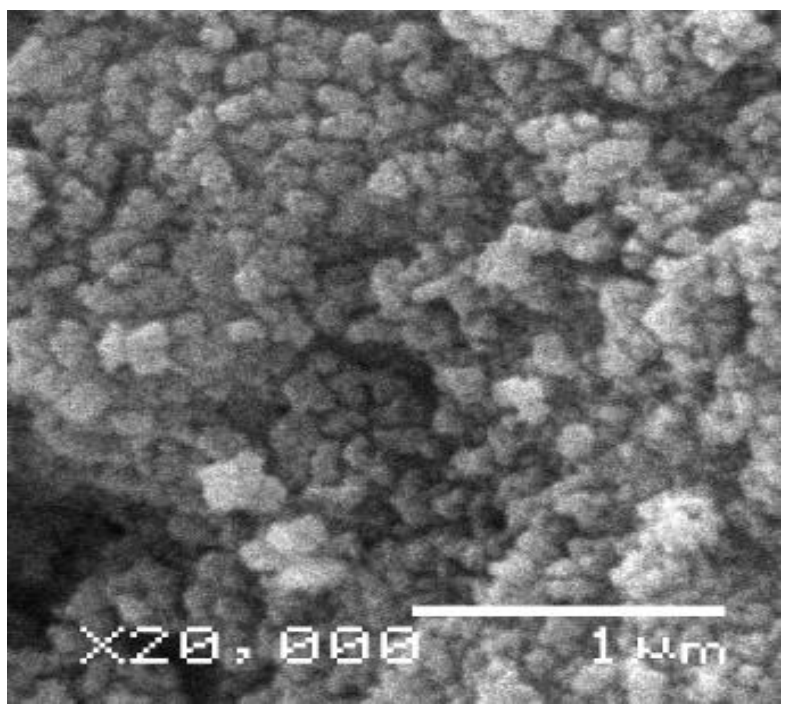

Gambar 4. Morfologi sampel $\mathrm{Fe}_{3} \mathrm{O}_{4}$ dengan lama pemanasan 5 jam

Berdasarkan hasil SEM untuk semua sampel, dapat dikatakan bahwa waktu pemanasan dan temperatur pemanasan sangat mempengaruhi distribusi ukuran partikel $\mathrm{Fe}_{3} \mathrm{O}_{4}$. Namun penelitian dengan template PEG ini tidak terlepas dari optimasi konsentrasi PEG, sehingga optimasi terhadap temperatur sintering bisa memberikan efek yang signifikan terhadap ukuran partikel $\mathrm{Fe}_{3} \mathrm{O}_{4}$. 
Hasil karakterisasi masing-masing sampel dengan suseptibilitas magnet, SEM dan XRD dapat dilihat pada Tabel 3.

Tabel 3. Data pengukuran kemagnetan, ukuran kristal dan ukuran partikel $\mathrm{Fe}_{3} \mathrm{O}_{4}$ hasil Suseptibilitas Magnet, XRD dan SEM

\begin{tabular}{lccc}
\hline \multicolumn{1}{c}{ Sampel } & $\begin{array}{c}\text { Suseptibilitas } \\
\text { Magnet } \\
\left(10^{-8} \mathrm{~m}^{3} / \mathrm{kg}\right)\end{array}$ & $\begin{array}{c}\text { Ukuran } \\
\text { Kristal }(\mathrm{nm})\end{array}$ & $\begin{array}{c}\text { Ukuran Partikel } \\
(\mathrm{nm})\end{array}$ \\
\hline $\begin{array}{l}\mathrm{Fe}_{3} \mathrm{O}_{4} \text { dengan waktu } \\
\text { pemanasan 3 jam }\end{array}$ & 76711,08 & 41,72 & $50-60$ \\
\hline $\begin{array}{l}\mathrm{Fe}_{3} \mathrm{O}_{4} \text { dengan waktu } \\
\text { pemanasan 4 jam }\end{array}$ & 20427,96 & 20,86 & $36-46$ \\
\hline $\begin{array}{l}\mathrm{Fe}_{3} \mathrm{O}_{4} \text { dengan waktu } \\
\text { pemanasan 5 jam }\end{array}$ & 118942,42 & 69,67 & $58-68$ \\
\hline
\end{tabular}

Berdasarkan Tabel 3, dapat dilihat bahwa ukuran kristal sebanding dengan suseptibilitas magnet, semakin kecil ukuran kristal maka suseptibilitas akan semakin turun dan sebaliknya, semakin besar suseptibilitas maka ukuran kristal akan mengalami kenaikan. Hal ini disebabkan karena nilai suseptibilitas sebanding dengan momen magnet induksi, dimana momen magnet induksi dipengaruhi oleh ukuran kristal (Olamei. dkk, 2011).

\section{KESIMPULAN}

Berdasarkan hasil penelitian yang dilakukan, dapat disimpulkan bahwa waktu dan temperatur pemanasan berpengaruh terhadap kemagnetan, ukuran partikel, maupun ukuran kristal material magnetik $\mathrm{Fe}_{3} \mathrm{O}_{4}$ yang dihasilkan. Pemanasan dengan waktu yang optimum diperoleh pada 4 jam dengan ukuran kristal $\quad 20,86 \mathrm{~nm}$ dan ukuran partikel terkecil antara $36-46 \mathrm{~nm}$ dan suseptibilitas magnetnya $20427,96 \times 10^{-8} \mathrm{~m}^{3} / \mathrm{kg}$. Dengan demikian nanopartikel magnetik $\mathrm{Fe}_{3} \mathrm{O}_{4}$ ini dapat dijadikan sebagai bahan baku industri material magnetik.

\section{DAFTAR PUSTAKA}

1. Aiguo, Yan, 2008, Solvothermal Synthesis And Characterization Of Size-Controlled Fe3O4 Nanoparticles, Journal Alloys and Compound Volume 458, Issues 1-2, 30 June 2008, Pages 487-491

2. Gao, Kuixiong, 1993, Polyethylene glycol as an embedment for microscopy and histochemistry. CRC Press. Page.1-10

3. Hunt, C. P., B. Moskowitz, S. K. Banerjee, 1995, Magnetic Properties of Rock and Minerals, in T.J Ahrens, ed, Rock Physics and Phase Relation, A.

4. Iida H, K. Takayanagi, T. Nakanishi, T. Osaka, 2007, Journal of Colloid and Interface Science 314:274-280

5. Olamei. N, F. Gosselin, dkk. 2011. "Magnetic microparticle of size optimization for susceptibility constrast imaging". Proc. Intl. Soc.Mag Reson. Med 19.

6. Perdana, Febi Angelia. 2010. "Sintesis Nanopartikel Fe3O4 dengan Template PEG1000 dan Karakterisasi Sifat Kemagnetannya”. Jurnal Materi dan Energi Indonesia. Vol 01, No $01: 1-6$.

7. Sholiha, lia kurnia, 2010. "Sintesis dan Karakteristik Partikel Nano Fe3O4 yang Berasal Dari Pasir Besi dan Fe3O4 Bahan Komersial (Aldrich)". Laporan Tugas Akhir Jurusan Fisika. Institut Teknologi Sepuluh Nopember, Surabaya Takayanagi, dkk. 2007. Journal of Colloid and Interface Science, Vol.314, Page.274-280. 